This is the peer reviewed version of Yapa, H. and Lees, J. (2013). "Rectangular Reinforced Concrete Beams Strengthened with CFRP Straps." J. Compos. Constr., which has been published on: http://dx.doi.org/10.1061/(ASCE)CC.1943-

5614.0000416

\title{
Rectangular Reinforced Concrete Beams Strengthened with CFRP Straps
}

\author{
Hiran D. Yapa ${ }^{1}$ and Janet M. Lees ${ }^{2}$
}

\begin{abstract}
Shear deficient reinforced concrete (RC) structures can be effectively strengthened using external prestressed carbon fibre reinforced polymer (CFRP) straps. Due to the presence of the external elastic straps, a strengthened beam can continue to carry significant load beyond the stages of crack plane slipping and internal shear stirrup yielding, and the concrete is subjected to high tensile strain levels. As a consequence, the concrete material models play a significant role in the context of modeling such behavior. The modified compression field theory (MCFT), which is a widely accepted shear theory for unstrengthened RC structures, incorporates the details of the stressstrain behavior of concrete. The MCFT also considers compatibility as a governing factor, which facilitates the inclusion of the strap system into the MCFT formulation. In the current study, modifications were investigated to model CFRP strap retrofitted RC beams associated with either uniform or non-uniform strap spacings. An experimental investigation on strengthened and unstrengthened rectangular RC beams was carried out to validate the MCFT predictions for various strap layouts. The validation process revealed that, in general, the MCFT was able to model the shear response of the retrofitted RC beams but the representation of the softening of the concrete compressive strain, and stress, was found to be influential in the determination of the ultimate load capacity.
\end{abstract}

Key words: Shear strengthening, RC beams, CFRP straps, MCFT

${ }^{1}$ Lecturer, Department of Civil Engineering, Faculty of Engineering, University of Peradeniya, Peradeniya, 20400, Sri Lanka. hiranyapa@gmail.com

${ }^{2}$ University Senior Lecturer, Department of Engineering, University of Cambridge, Trumpington Street, Cambridge, CB2 1PZ, UK. jmL2@eng.cam.ac.uk 


\section{Introduction}

The strengthening of shear-deficient reinforced concrete (RC) structures using external fibre reinforced polymer (FRP) reinforcement can avoid, or delay, the imposition of weight restrictions and/or the demolition and reconstruction of a structure. A system consisting of external, vertical, unbonded carbon FRP (CFRP) straps (as shown in Fig. 1) has been investigated as a possible method to retrofit RC beams in shear [Lees et al. 2002]. Unlike external surface bonded systems [Teng et al. 2003], a strap forms a closed loop and is not bonded to the concrete surface so the absence of debonding issues is an extra advantage. Furthermore, the use of prestressed straps is an efficient use of the high strength associated with the FRP material. By applying compression to the top and bottom faces of the beam, the unbonded straps act to confine the concrete and, as a consequence, are capable of reducing shear crack widths and the extent of crack propagation [Kesse \& Lees 2007]. The serviceability performance of the beam is therefore improved.

The CFRP strap reinforcing element, which was originally developed by Winistörfer [1999], is made by winding layers of thin (typically between $0.12 \mathrm{~mm}$ and $0.16 \mathrm{~mm}$ thick) CFRP thermoplastic tape around the beam. The two outermost tape layers are welded so as to form a complete self-anchored nonlaminated loop [Lees \& Winistörfer 2011]. Two profiled steel pads can be used as bearings at the top and bottom beam surfaces to provide a smooth support for the CFRP strap. A further approach is to use an under-slab installation technique where the strap is supported in a groove through a slot drilled in the concrete which avoids the need for a top bearing pad [Hoult \& Lees 2009]. To prestress the strap, the top (or bottom) steel pad is placed on a slotted square steel plate prior to strap installation (see Fig. 1) and is subsequently lifted during the prestressing procedure. Metal shims are inserted into the gap created between the plate and the beam to lock in the prestress.

In an unstrengthened RC beam with insufficient internal vertical steel shear reinforcement, when shear cracks appear, any internal steel web reinforcement carries additional stress and the beam behavior becomes nonlinear. At high load levels, the crack opening increases significantly, the crack planes start to slip, and the steel web reinforcement tends to yield. The aggregate interlocking mechanism and the concrete contribution towards the shear strength deteriorate [Yapa 2011]. If however the beam 
is strengthened with external CFRP straps, the strap force, which consists of the initial prestress force and the additional force created due to the crack opening in the beam, also contributes to the beam shear strength [Kesse \& Lees 2007]. After the steel yields, since the CFRP straps are elastic, they can continue to sustain further load until the strap fails. When the strap force increases so does the confinement to the concrete which restrains further crack opening and slipping along the crack planes [Yapa \& Lees 2011]. The behavior of a CFRP strap strengthened beam is therefore complex and consists of several transitions between different stages of behavior.

The modified compression field theory (MCFT) developed by Vecchio \& Collins [1986] is a shear theory which incorporates the stress-strain relationships of reinforced concrete. Lees et al. [2002], Hoult \& Lees [2011] and Yapa \& Lees [2011] have conducted studies to investigate the possibility of using the MCFT to predict the behavior of strap strengthened beams. Yapa \& Lees [2011] noted cases where the MCFT failure mode predictions did not match those observed experimentally and suggested that the compression softening model and extensive cracking were possible reasons for this discrepancy. These aspects will be discussed in the current study and the MCFT predictions will be verified using the results of an experimental investigation consisting of six rectangular RC beams.

\section{Modified compression field theory (MCFT)}

The MCFT (Vecchio \& Collins [1986]) is used for the analysis of cracked reinforced concrete. The theory takes into account equilibrium, compatibility, and concrete material models that consider the effects of biaxial stress. It primarily deals with average stresses and strains, and assumes that the principal directions of stress and strain are the same. The MCFT has the capability to predict the full response of cracked RC members which are subjected to shear and/or torsion. However, the relative complexity of the formulation due to a relatively large number of equations is a drawback. Since the CFRP strap reinforcement will potentially result in a further strength gain even after crack slipping and/or internal transverse steel yielding, the initial focus is the concrete material models within the MCFT. The full details of the MCFT can be found elsewhere [Vecchio \& Collins 1986, Collins \& Mitchell 1987]. 


\section{Concrete in tension}

The MCFT material model for concrete in tension is shown in Fig. 2(a). The principal tensile stress $f_{c 1}$ vs. principal tensile strain $\varepsilon_{1}$ relationship, which applies from the onset of concrete cracking, is expressed as;

$$
f_{c 1}=\frac{0.33 \sqrt{-f_{c}^{\prime}}}{1+\sqrt{500 \varepsilon_{1}}}
$$

A limiting constraint related to the slip along the crack planes is;

$$
f_{c 1}=\frac{0.18 \sqrt{-f_{c}^{\prime}}}{0.31+24 w /\left(a_{g}+16\right)} \tan \theta
$$

where $f_{c}^{\prime}, w, a_{g}$, and $\theta$ are the cylinder compressive strength of concrete, crack width, maximum aggregate size, and inclination of the principal compressive strain direction relative to the $x$ (longitudinal) direction, respectively. The crack width can be calculated as,

$$
w=\frac{\varepsilon_{1}}{\frac{\sin \theta}{s_{X}}+\frac{\cos \theta}{s_{Z}}}
$$

where $s_{x}$ and $s_{z}$ are the crack spacings in the $x$ and $z$ (vertical) directions. In the current work, as suggested by Vecchio \& Collins [1986], these are taken as the spacing of the respective internal reinforcement. With increasing $\varepsilon_{1}$ (and increasing cracking), the concrete in tension becomes weaker and, after the onset of slip along the crack planes, the rate of softening increases (see Fig. 2(a)). The principal tensile strain at the crack plane slipping stage $\left(\varepsilon_{1 \_s l i p}\right)$ corresponds to the intersection of the curves represented by Eqns. 1 and 2. Fig. 2(b) shows the behavior of $\varepsilon_{1 \_s l i p}$ vs $\theta$ assuming $s_{x}, s_{z}$ and $a_{g}$ are $200 \mathrm{~mm}, 200 \mathrm{~mm}$ and $10 \mathrm{~mm}$ respectively. $\varepsilon_{1 \_s l i p}$ is sensitive to $\theta$, therefore a full MCFT evaluation is required to identify $\varepsilon_{1 \_ \text {slip }}$ for a given structure.

\section{$\underline{\text { Concrete in compression }}$}

Duthinh [1999] carried out a comparison of compression softening models for the MCFT in the context of the shear strength of reinforced concrete and found that the choice of model dictated whether the ultimate failure mode was correctly predicted. In the original 1986 version of the MCFT, Vecchio \& Collins [1986] proposed a concrete compression model where the peak stress $f_{c 2 \max }$ softened depending on the principal tensile strain, $\varepsilon_{1}$ : 


$$
f_{c 2 \max }=\beta f_{c}^{\prime} \text { where } \beta=\left(0.80-0.34 \varepsilon_{1} / \varepsilon_{c}^{\prime}\right)^{-1} \leq 1
$$

but the compressive strain, $\varepsilon_{c}^{\prime}$, associated with the maximum cylinder strength remains constant (see Fig. 3(a)). In 1993, Vecchio \& Collins showed that this softening model could generally predict the shear response of RC structures but, in certain instances, a strain softening model was advantageous. Vecchio \& Collins' [1993] Model A (see Fig. 3(b)) uses a Thorenfeldt base curve, where both the principal compressive stress, $f_{c 2}$, and strain, $\varepsilon_{2}$, are subjected to a softening factor $\delta$ :

$$
\delta=\frac{1}{1.0+K_{c} K_{f}}
$$

where, $K_{c}=0.35\left(\frac{-\varepsilon_{1}}{\varepsilon_{2}}-0.28\right)^{0.80} \geq 1.0$ and $K_{f}=0.1825 \sqrt{-f_{c}^{\prime}(\mathrm{MPa})} \geq 1.0$. In the ascending branch, the maximum principal compressive stress and strain are found as $f_{c 2 \text { max }}=\delta f_{c}^{\prime}$ and $\varepsilon_{2 \max }=\delta \varepsilon_{c}^{\prime}$ where $\varepsilon_{c}^{\prime}$ is usually taken as -0.002 [Vecchio \& Collins 1986]. The principal compressive stress is then given by,

$$
f_{c 2}=f_{c 2 \max } \frac{n\left(\frac{\varepsilon_{2}}{\varepsilon_{2 \max }}\right)}{(n-1)+\left(\frac{\varepsilon_{2}}{\varepsilon_{2 \max }}\right)^{n k}}
$$

where, $n=0.80-\frac{f_{c 2 \max }(\mathrm{MPa})}{17}$ and $k=1$ for $-\varepsilon_{2} \leq-\varepsilon_{2 \max }$. At the peak, the stress then plateaus until a strain of $\varepsilon_{c}^{\prime}$. The stress $f_{c 2 d}$ in the descending branch (when $\left.-\varepsilon_{2}>-\varepsilon_{c}^{\prime}\right)$ is calculated using $f_{c 2 \max }=f_{c}^{\prime}$ and $\varepsilon_{2 \max }=\varepsilon_{c}^{\prime}$ in Eqn. 6; where $n=$ $0.80-\frac{f_{c}^{\prime}(\mathrm{MPa})}{17}$ and $k=0.67-\frac{f_{c}^{\prime}(\mathrm{MPa})}{62}$ and setting $f_{c 2 d}=\delta f_{c 2}$. In Fig. 3(c), the stress-strain curves for the 1986 and 1993 A models are compared for two principal tensile strain values (selected for future reference) and a typical concrete strength of $f_{c}^{\prime}=-35 \mathrm{MPa}$. In the equations and figures presented here, the terms related to compression (e.g. $f_{c}^{\prime}, \varepsilon_{2}, f_{c 2}$ ) are considered as negative. As will be discussed later in the paper, the $1993 \mathrm{~A}$ model was found to be better than the 1986 model when predicting the retrofitted RC beam failure behavior. It is of note that this conclusion tallies with Vecchio \& Collins’ [1993] and Duthinh’s [1999] outcomes. Yapa \& Lees [2011] attempted to model the behavior of some beams in the experimental series discussed in the current paper using the MCFT together with the 1986 model. As mentioned previously, they also found that, generally, the failure load and mode could not be accurately predicted in that context. Hence, the main focus will be the results associated with the 1993 A model. 


\section{$\underline{\text { Onset of slip and compression demand }}$}

Unstrengthened shear deficient RC beams typically fail after the onset of the yielding of the transverse reinforcement. In strap strengthened beams, provided the concrete does not fail, the strap can continue to sustain load until $\varepsilon_{z}$ reaches the ultimate strap strain. For example, for a strap with an ultimate strain of around $1.3 \%$ and an initial prestress of $25 \%$ or $50 \%$, this would equate to a residual strain capacity of 0.00975 or 0.00625 respectively. This extra capacity then places a higher demand on the concrete compressive resistance under large concurrent principal tensile strains. As shown in Fig. 3(c), an increase in $\varepsilon_{1}$ will cause a greater softening of concrete in compression. For a given principal tensile strain and at relatively small levels of $\left|\varepsilon_{2}\right|$, the behavior of both the 1986 and 1993 A compression models are similar. But at higher values of $\left|\varepsilon_{2}\right|$, the responses deviate and the peaks in the two curves are notably dissimilar.

\section{Application of the MCFT to CFRP strap strengthened RC beams}

The application of the full MCFT, where the beam cross section is subdivided into layers and subjected to both shear and flexure, is most suited for implementation in a computer-based program [Collins \& Mitchell 1987]. However, since the shear flow distributions in typical RC members are fairly uniform between the top and bottom reinforcement, Collins \& Mitchell 1987 have proposed an approximate method where a constant shear stress distribution is assumed for an effective shear area of depth $d_{v}$ and width $b_{v}$ can be used. Here, $d_{v}$ can be taken as the flexural lever arm but need not be taken as less than $0.9 d$ ( $d$ is the effective depth); $b_{v}$ is the effective width of the shear area which is equal to the web width $b_{w}$. It is further assumed that the longitudinal strain at the mid depth of the beam corresponds to the assumed shear stress, and a constant principal strain (or stress) direction applies for the whole depth of the beam. The analysis is performed for increments of $\varepsilon_{1}$ and bending moment. A shear force vs. bending moment envelope is constructed and the critical shear strength is identified [Bentz 2000]. The detailed application of the MCFT is discussed elsewhere [Collins \& Mitchell 1987].

When a RC beam is strengthened in shear with unbonded CFRP straps, a vertical force is applied to the top and bottom surfaces of the beam through the strap supports. Lees et al. [2002] suggested that for uniformly distributed CFRP straps an average 
vertical stress, $f_{Z_{-} F R P}$, can be assumed at the mid-depth of a RC beam. The CFRP strap forces can then be included in the vertical equilibrium of a free body. The MCFT equilibrium equations are then:

$$
\begin{gathered}
f_{x}=\rho_{s x} f_{s x}+f_{c 1}-v \cot \theta \\
f_{z}=\rho_{s z} f_{s z}+f_{Z_{-} F R P}+f_{c 1}-v \tan \theta \\
v=\left(f_{c 1}-f_{c 2}\right) /(\tan \theta+\cot \theta)
\end{gathered}
$$

where $v$ is the shear stress, $\rho_{s x}, \rho_{s z}$, are the reinforcement ratios for the longitudinal and vertical steel, and $f_{x}, f_{z}$ and $f_{s x}, f_{s z}$ are the total, and steel stress, in the $x$ and $z$ directions respectively.

For nonuniform strap arrangements, or large strap spacings, Yapa [2011] undertook elastic uncracked finite element (FE) modeling to identify the vertical stress distribution due to the strap forces. The approach was similar to that used by Acevedo et al. [2009] to model RC slabs subjected to clamping stresses. Whereas the stresses due to uniformly spaced CFRP straps were broadly similar to the average case, with nonuniform strap spacings, relatively stronger and weaker regions exist and an average vertical stress was not representative of the whole shear span [Yapa 2011]. It was instead necessary to distinguish between regions (using a representative average vertical stress) and to perform the MCFT analysis for each region to determine which region is most shear critical. The vertical stress distribution due to the strap force was symmetric and triangular. The mid-depth vertical stresses became negligible at a distance of approximately the beam effective depth, $d$, on either side of a strap. The distribution for two or more CFRP straps could be obtained by superposing the vertical stresses associated with a single strap. The clamping stress distribution due to either the beam support or load point is also distributed in a nearly triangular shape. Furthermore, at the beam mid-depth, approximately 25\% of the total vertical force is distributed as vertical stresses within a distance of roughly $d$ measured into the shear span. Using these approximations, it was proposed that, for a simply supported rectangular beam under four point bending, the beam could be subdivided into a region between the support and the first strap (R1), a strengthened region where different strap spacings can be accommodated (R2), and a region 
between the last strap and the load point (R3) (see Fig. 4(a)). Within each of these regions, the approximated average vertical stress at the beam mid-depth is;

$$
\begin{aligned}
f_{Z_{-} F R P_{-} R 1}= & \frac{\frac{V}{4}+\frac{F_{F R P 1}}{2}}{b_{v} s_{F R P 1}} \times k_{C_{-} R 1} \\
f_{Z_{-} F R P_{-} R 2 i}= & \frac{\frac{F_{F R P i}}{2}+\frac{F_{F R P(i+1)}}{2}}{b_{v} s_{F R P(i+1)}} \times k_{C_{-} R 2 i} \quad i=1 \text { to } n-1 \\
f_{Z_{-} F R P P_{-} R 3}= & \frac{\frac{F_{F R P n}}{2}+\frac{V}{4}}{b_{v} s_{F R P(n+1)}} \times k_{C_{-} R 3}
\end{aligned}
$$

where $V, F_{F R P}, b_{v}, s_{F R P}, n$ and $k_{c}$ are the shear force, CFRP strap force, width of beam shear area, length of section under consideration, number of straps and a coefficient $\left(k_{c} \leq 1\right)$ which reflects the presence of local unconfined regions. These unconfined areas can occur within strengthened regions due to the triangular vertical stress distribution (see Fig. 4). On the basis of FE analyses, the coefficient $k_{c}$ was defined as the ratio of the confined area to the total shear area in each region. Eqns. 10-12 can then be used to represent the 'smeared' vertical stress taking into account unconfined regions. Assuming $d_{v}=0.9 d$, the proposed relationship between $k_{c}$ and $s_{F R P} / d$ for $s_{F R P} \leq 2 d$, is shown schematically in Fig. 4(b). It was assumed that the average vertical stress was negligible when $s_{F R P}>2 d$ but in the design of a strengthening system, a much more conservative limit on the strap spacing would be required. This is the subject of further work.

\section{Implementation}

A summary of the implementation of the MCFT method for CFRP strap strengthened beams will be presented here. For full details, see Yapa [2011] (note that the 1993 A model was denoted as 'concrete softening model B' in Yapa [2011]). Each beam region, bounded by either two straps, a strap and a beam support, or a strap and a load point, is selected to perform the analysis. The associated bending moment is taken halfway along the region. For a given value of $\varepsilon_{1}$, a crack angle $\theta$ and a vertical strain $\varepsilon_{z}$ are assumed. The steel shear link stress $f_{s z}$ and force in the strap $F_{F R P}$ corresponding to the assumed $\varepsilon_{z}$ are then calculated. Note that, as proposed by Hoult \& Lees [2009] the strap 'height', $h_{F R P}$ is approximated as the distance between the extreme faces of the support pads so the strap strain is $\varepsilon_{z} h / h_{F R P}$. The stress $f_{c 1}$ can be 
calculated from Eqns. 1 or 2, as appropriate. Equilibrium Eqn. 8 (which includes the vertical stress due to the CFRP strap force) and Eqn. 9 are used to calculate the shear stress $(v)$ and principal compressive stress $\left(f_{c 2}\right)$. It is then necessary to iterate through the concrete material model equations to find $\varepsilon_{2}$. Mohr's circle of strain is used to back-calculate $\varepsilon_{z}$ and to check that the calculated $\varepsilon_{z}$ agrees with the original assumed value (if not the original assumption is updated). The longitudinal strain, $\varepsilon_{x}$, and stress, $f_{s x}$, can then be found. The final step is to confirm whether horizontal equilibrium is satisfied by balancing the longitudinal force due to shear, and that due to the applied bending moment. Here, the longitudinal stain in the tensile reinforcement is to be found proportional to the mid-depth strain, $\varepsilon_{x}$. More details can be found elsewhere [Collins \& Mitchell 1987]. If equilibrium is not satisfied, the calculations are repeated with different $\theta$ and $\varepsilon_{z}$ values.

The same procedure is carried out for increments of $\varepsilon_{1}$ and each region in the shear span. The critical shear region, critical shear response and ultimate shear capacity of the strengthened beam can then be determined. Note that when a MCFT analysis is performed for a region adjacent to the beam support or load point, the shear force itself has an influence for the imposed vertical stress (see Eqns. 10, 12). It is therefore necessary to assume a shear force along with $\theta$ and $\varepsilon_{z}$ at the beginning of the analysis and compare the assumed $V$ with that obtained in the final step. As a consequence, additional iterations are required.

\section{Experimental investigation}

An initial experimental investigation reported elsewhere (Yapa \& Lees [2011]) was extended to validate the MCFT predictions and explore the influence of the material modelling. In total six rectangular RC beams including a control beam (B1) and five CFRP strengthened beams (B2-B6) were tested. The CFRP strap locations, number of straps, strap stiffness and strap prestress were varied. B3 was nearly identical to B2 and the results were similar. So for conciseness, only the results from B2 will be reported.

\section{Specimens}

To promote shear failures, the beams were designed with a considerable difference between their ultimate load carrying capacity based on flexural strength and shear 
strength. The beams were simply supported with a pin bearing at one support and roller bearing at the other. The overall beam length was $2400 \mathrm{~mm}$. The four point bending test layout consisted of two shear spans of $690 \mathrm{~mm}$, a $620 \mathrm{~mm}$ constant moment region and two $200 \mathrm{~mm}$ overhangs. The cross section had a width of $105 \mathrm{~mm}$ and a height of $280 \mathrm{~mm}$ (see Fig. 5). The internal steel reinforcement was the same for all the experimental beams. The longitudinal steel consisted of four $16 \mathrm{~mm}$ diameter bars as tensile reinforcement (in two layers, $d=229 \mathrm{~mm}, \rho_{x}=3.3 \%$ ) and four 12 mm diameter bars as compression reinforcement (in two layers). The internal transverse reinforcement (shear stirrups) was $4 \mathrm{~mm}$ diameter smooth bars with a spacing of $200 \mathrm{~mm}$. For strengthening, either two or three CFRP straps having either five or ten tape layers were considered. The level of strap prestress was limited to $25 \%$ to avoid the possibility of a strap failure [Kesse \& Lees 2007] and thereby facilitate the observation of the concrete/strap interaction at large principal tensile strains. Note that the CFRP strap configurations were also designed to investigate the issue of the optimum shear strengthening. This subject is beyond the scope of this paper, but has been discussed elsewhere [Yapa 2011].

The beam layouts are shown in Fig. 5. In B2, two, 10 layer, 25\% prestressed CFRP straps were located at a distance of $270 \mathrm{~mm}$ and $470 \mathrm{~mm}$ from the beam support to obtain a high level of shear strengthening. Two 10 layer, 25\% prestressed CFRP straps were located in B4 at a distance of $110 \mathrm{~mm}$ and $270 \mathrm{~mm}$ from the beam support respectively to achieve a low level of shear strengthening and a highly nonuniform strap spacing. In B5, three, 5 layer, 25\% prestressed CFRP straps were positioned (smaller material usage relative to B2) at distances of $270 \mathrm{~mm}, 350 \mathrm{~mm}$ and $470 \mathrm{~mm}$ to obtain a high level of shear strengthening. In B6, a strap layout similar to that of B5 but with a lower strap prestress of 5\%, was investigated to demonstrate the possibility of achieving sufficient shear enhancement with a low strap prestress.

\section{Materials}

Rapid hardening cement was used and the target concrete cube strength at 28 days was $40 \mathrm{MPa}$. The fine aggregate complied with grading zone 3 and the coarse aggregate was $10 \mathrm{~mm}$ uncrushed gravel. Concrete control cubes $(100 \times 100 \times 100 \mathrm{~mm})$ and cylinders $(100 \times 200 \mathrm{~mm})$ were tested on the same day as each beam. The average cube strengths for the beams at the time of testing have been summarized in Table 1. 
Due to an unfortunate mixing error, B1 and B4 gained a higher cube strength (61.8 $\mathrm{MPa}$ ) than anticipated. Based on tensile tests, the average yield stresses of the $4 \mathrm{~mm}$, $12 \mathrm{~mm}$ and $16 \mathrm{~mm}$ diameter bars were found to be $475 \mathrm{MPa}, 519 \mathrm{MPa}$ and $496 \mathrm{MPa}$ respectively. The CFRP straps were formed from a continuous $12 \mathrm{~mm}$ wide by $0.16 \mathrm{~mm}$ thick CFRP tape consisting of unidirectional CFRP fibers embedded in a thermoplastic resin. The modulus of elasticity of the strap was approximately $120 \mathrm{GPa}$ with an ultimate strain of around $1.3 \%$.

\section{Instrumentation, strap installation and testing}

The total applied load was measured using a load cell. The strain gauge locations in the critical shear span (where failure occurred) are shown in Fig. 5 where the strain gauges on the transverse internal reinforcement and CFRP straps are designated as TR\# and CF\#, respectively. The strain gauge locations were selected to be close to the potential failure planes shown in Fig 5. Since the straps were un-bonded, the strain gauges on the CFRP straps were located near to the mid height of the straps, regardless of potential crack orientations. Linear Resistance Displacement Transducers were used to measure the displacement along the beam.

Seven days after casting, the straps were installed on the strengthened beams. The CFRP tape was wound around the pad supports until the desired number of layers was reached and the two outermost tape layers were welded by inserting thermoplastic material in between the tape layers and applying heat to form a strap. The width of the top and bottom bearing pads was $30 \mathrm{~mm}$ with the exception of the bottom bearing pads in B4, which had a width of $75 \mathrm{~mm}$. The distance between the extreme faces of the support pads, $h_{F R P}$, was $350 \mathrm{~mm}$. The straps were prestressed to the desired forces using a hydraulic jack and a reaction frame placed on the beam.

The beams were simply supported and tested until failure using a 500 ton Amsler loading rig, see Fig. 6. To avoid local bearing failures, $100 \times 105 \mathrm{~mm}$ steel bearing pads (with the exception of B1 where the loading point pads were $105 \times 140 \mathrm{~mm}$ ) were placed at the beam supports and loading points. Load control was used but, for safety reasons, the test was switched to displacement control as the beam approached failure. 


\section{Experimental results}

The load-displacement curves and photos of the beam failures are presented in Figs. 7 and 8 respectively. The peak shear capacities for beams B1, B2, B4, B5, and B6 were $83.1 \mathrm{kN}, 104.7 \mathrm{kN}, 92.9 \mathrm{kN}, 114.8 \mathrm{kN}$, and $107.5 \mathrm{kN}$ respectively. Sudden shear failures were observed in B1 and B4 whereas beams B2, B5 and B6 failed in shear but exhibited a more ductile failure behavior. B5 also experienced a partial flexural failure. The theoretical flexural capacities of the beams were between 110-115 kN. None of the straps failed at the peak load, but the straps in B5 and B6 failed postpeak. The crack openings in B6 were greater than in the other retrofitted beams.

The load-displacement curves indicate that up to load levels $\approx 35 \mathrm{kN}$, the beam behavior was fairly similar. Thereafter, the response became nonlinear and differences were noticeable. Near the ultimate load level, the stiffness of the beams deteriorated considerably. With the exception of B4, deliberately designed to obtain a low level of shear enhancement, the strengthened beams were at least $25 \%$ stronger than the unstrengthened control beam, B1. Allowing for the higher concrete strength in B1, a like-for-like comparison would suggest the enhancement could be closer to $40 \%$.

\section{Comparison with MCFT predictions}

The MCFT predictions for the critical shear regions of the beams were compared with the experimental observations. The critical regions, the distance from the support to the midpoint of the critical shear region and the confined area ratios $\left(k_{c}\right)$ are shown in Fig. 8. For B5 and B6, due to the close strap arrangement and for simplicity, the region bounded by Strap1 and Strap3 was considered to be a single region and proved to be critical. The MCFT predictions provided a reasonable approximation of the ultimate shear strengths where the mean of the ratio of the predicted to experimental failure load was 0.92 with a standard deviation of 0.08 (see Table 1). More detailed MCFT results for the critical shear regions are tabulated in Table 2. According to the predictions for $\mathrm{B} 1$, the crack planes starts to slip at a shear load of $63.4 \mathrm{kN}$ and the shear links yield at a load of $66.2 \mathrm{kN}$, the peak load for the beam. Ultimately, at a load of $60.0 \mathrm{kN}$, the beam collapses due to concrete crushing. Fig. 9(a) shows that the MCFT shear link stress prediction for B1 is a reasonable approximation of the experimental behavior. In the strengthened beams B2, B4, B5 and B6, the crack planes start to slip at loads of $90.7 \mathrm{kN}, 83.4 \mathrm{kN}, 94.5 \mathrm{kN}$ and $73.3 \mathrm{kN}$ respectively and 
then, with increasing load, the internal steel stirrups yield at $97.5 \mathrm{kN}, 87.7 \mathrm{kN}$, $101.6 \mathrm{kN}$ and $83.2 \mathrm{kN}$ respectively. However, due to the presence of the CFRP straps, even after the internal steel has yielded, additional load can be sustained and the retrofitted beams are predicted to fail by concrete crushing. Strap failure was not predicted to occur. Hence, the MCFT has accurately predicted the beam failure modes. Figs. 9(b) - (e) illustrate a comparison of the shear link stress, CFRP strap force and crack width readings for the four beams along with the MCFT results. The MCFT prediction for the shear link behavior can generally be regarded as a reasonable approximation. The MCFT predictions for the strap force and crack width are fairly similar to the experimental results at low levels of loading. But the predicted and experimental results deviate near the ultimate stage of loading. The potential reason could be the excessive deformations and rotations near the ultimate load of the beams, which is not addressed in the MCFT formulation. For B4, the critical shear crack did not pass through the strap (see Fig. 8) and so the strap force is not necessarily representative of the region considered in the MCFT analysis.

The peak load of the unstrengthened beam occurs when $\varepsilon_{2}=-0.00014$ and $-\varepsilon_{1} / \varepsilon_{2}$ $>20$. With the exception of B4, the retrofitted beams approach their peak strengths at $\varepsilon_{2}$ values of $\approx-0.0006$ with $-\varepsilon_{1} / \varepsilon_{2}$ ratios of between 8 and 10 . All the MCFT failures were limited by the peak softening compressive stress. Whereas this limit was reached in the post-peak response of the unstrengthened beam, for the strengthened beams this dictated the ultimate shear capacity. So the concrete compression model plays a role in the prediction of the final failure of the retrofitted beams. Consider the MCFT results for B2 shown in Table 2. When $\varepsilon_{1}=0.0027, \varepsilon_{2}=$ -0.00026 and Fig. 3(c) shows that at such strains, both the 1986 and $1993 \mathrm{~A}$ compression models behave similarly. However, when $\varepsilon_{1}=0.005, \varepsilon_{2}$ is -0.00061 . This strain level corresponds to the maximum stress in the $1993 \mathrm{~A}$ model but is only a fraction of the peak strength in the 1986 model. Thus, the 1986 model would not identify these strains, and corresponding shear strength, as failure conditions for B2. It is of note that in Yapa \& Lees [2011], where failure mode predictions for B2 based on the 1986 compression softening model were reported, that this beam was predicted to fail in flexure. 


\section{Implications}

The MCFT results can be used to investigate further aspects of the behavior of the strap strengthened beams. Since the concrete properties and strap arrangements varied across the experimental beams, the following parametric study will instead use a common baseline for comparison. In the study, the cross-section and internal steel were as shown in Fig. 5(a), the concrete strength was fixed at $35 \mathrm{MPa}$ and a strap spacing of $200 \mathrm{~mm}$ was assumed. A beam with 10 layer straps with an initial prestress level of 25\%, and an equivalent unstrengthened beam are considered.

The MCFT equilibrium equations were used to explore the variation of the shear stress $v$, and the required compressive stress, $f_{c 2 \_ \text {required }}$, with respect to $\varepsilon_{1}$. It is important to note that these are not necessarily the actual MCFT solutions since the full set of MCFT equilibrium, compatibility and material equations have not been satisfied. Nevertheless, the results provide insight into the behavioral trends of a strengthened and unstrengthened beam. If the transverse steel has yielded, the force in the steel is known and, if slip has occurred, the concrete tensile stress is limited by the shear stress along the crack (Eqn. 2). For this post-slip, post-yield stage, say with $\varepsilon_{1}>0.003$, then for an assumed crack angle and value of $\varepsilon_{2}$, Eqn. 8 can be rearranged to calculate the shear stress $v$ as a function of $\varepsilon_{1}$. The associated compressive strength demand can then be back-calculated from Eqn. 9. The normalized results have been plotted in Fig. 10 for assumed crack angles between $28^{\circ}$ and $24^{\circ}$. For the values considered here, the calculated shear and concrete stress demand curves are not very sensitive to $\varepsilon_{2}$ and so $\varepsilon_{2}$ was assumed to be -0.0005 . These plots show that, for a given angle, both the shear capacity and the required principal compressive stress of the unstrengthened beam reduce with increasing $\varepsilon_{1}$. In contrast, the presence of the prestressed straps leads to an increase in shear capacity with increasing $\varepsilon_{1}$ but this increase puts a greater demand on the concrete in compression. For both the strengthened and unstrengthened case a reduction in the crack angle will put a greater demand on the concrete component. The peak concrete compressive strength $f_{c 2 \max }$ for the 1986 and 1993 A concrete material models have been superposed on Fig. 10(b). Since the 1993 Model A depends on $\varepsilon_{2}$ (Eqns. 5 and 6), $\varepsilon_{2}$ was taken as either -0.0003 or -0.0006 . It can be seen that, depending on the ratio of $\varepsilon_{1} / \varepsilon_{2}$ and the angle, the 1993 A model peak stress can control the capacity of the strengthened beam. 


\section{Further considerations}

Existing structures may be damaged prior to strengthening and the experiments and theory presented here did not take this into account. Work by Dirar et al. [2013] has investigated the influence of a pre-existing crack pattern on the behavior of CFRP strap strengthened T-beams and found that the ultimate load capacities of the strengthened beams were not significantly dependent on existing damage. Appropriate concrete models and representations of phased loading conditions are necessary when conducting analyses to reflect damage.

In the current work, a sectional model with the assumption of a constant shear stress distribution and a vertical stress approximation was combined with a concrete compressive strain softening model. This generally gave good predictions of the experimental beam results. One advantage of the sectional approach, and the assumptions regarding the stress distributions, is that it is computationally more straightforward. To fully assess these assumptions, benchmarking against layer by layer approaches, or finite element analyses would be required e.g. to explore the implications of linear or non-linear stress distributions.

\section{Conclusions}

The MCFT can be extended to model the behavior of CFRP strap strengthened beams and an experimental investigation, consisting of a control beam and beams retrofitted with various CFRP strap layouts, was used to test the validity of the proposed MCFT approach. Unlike the unstrengthened beam, the strengthened beams continued to carry increased loads after the yielding of the transverse steel and the slip along the crack planes. The behavior of the concrete in compression with large concurrent principal tensile strains was therefore important and the material compression model determined the prediction of the failure conditions. The MCFT conservatively predicted the ultimate loads of the beams with a mean ratio of the predicted to the experimental failure load of 0.91 with a standard deviation of 0.08. The steel, CFRP reinforcement, and crack opening behavior, were predicted with a reasonable accuracy. Similarly, the shear response transitions at the crack plane slipping and transverse steel yielding stages were fairly captured by the MCFT modeling. 


\section{Acknowledgements}

The first author is grateful for the financial support provided by the Cambridge

Commonwealth Trust, the Overseas Research Studentship and the Churchill College. The authors are also appreciative of the technical support and assistance provided by EMPA, Dr. N.A. Hoult, Dr. C.T. Morley, Mr. M.R. Touhey and Mr. S.J. Holder.

\section{References}

Acevedo, A.B., Bentz, E.C. and Collins, M.P., 2009, Influence of Clamping Stresses in the Shear Strength of Concrete Slabs Under Uniform Loads, Journal of Earthquake Engineering, 13(S1), 1-17.

Bentz, E.C., 2000, Sectional Analysis of Reinforced Concrete, PhD Thesis, Department of Civil Engineering, University of Toronto.

Collins, M.P. and Mitchell, D., 1987, Prestressed Concrete Basics, Canadian Prestressed Concrete Institute, Ontario.

Dirar, S., Lees, J. M. and Morley, C., 2013 Precracked Reinforced Concrete T-Beams Repaired in Shear with Carbon Fiber-Reinforced Polymer Straps, ACI Structural Journal (to appear, Sept/Oct)

Duthinh, D., 1999, Sensitivity of Shear Strength of Reinforced Concrete and Prestressed Concrete Beams to Shear Friction and Concrete Softening According to Modified Compression Field Theory, ACI Structural Journal, 96(4), 495-508.

Hoult, N.A. and Lees, J.M., 2009, Efficient CFRP Strap Configurations for the Shear Strengthening of Reinforced Concrete T-Beams, ASCE Journal of Composites for Construction, 13(1), 45-52.

Hoult, N.A. and Lees, J.M., 2011, Time-Dependent Behavior of RC Beams Retrofitted with CFRP Straps, ASCE Journal of Composites for Construction, 15(1), 75-84.

Kesse, G. and Lees, J.M., 2007, Experimental Behaviour of Reinforced Concrete Beams Strengthened with Prestressed CFRP Shear Straps, ASCE Journal of Composites for Construction, 11(4), 375-383.

Lees, J.M. and Winistörfer, A.U., 2011, Non-laminated FRP Strap Elements for Reinforced Concrete, Timber and Masonry Applications, ASCE Journal of Composites for Construction 15(2), 146-155.

Lees, J.M., Winistörfer, A.U. and Meier, U., 2002, External Prestressed Carbon Fiber Reinforced Polymer Straps for Shear Enhancement of Concrete, ASCE Journal of Composites for Construction, 6(4), 249-256. 
Teng, J.G., Chen, J.F., Smith, S.T. and Lam, L., 2003, Behaviour and Strength of FRP-Strengthened RC Structures: A State-of-the-art Review, Proceedings of the Institution of Civil Engineers - Structures and Buildings, 156(1), 51-62.

Vecchio, F.J. and Collins, M.P., 1986, The Modified Compression Field Theory for Reinforced Concrete Elements Subjected to Shear, ACI Structural Journal, 83(2), 219-231.

Vecchio, F.J. and Collins, M.P., 1993, Compression Response of Cracked Reinforced Concrete, ASCE Journal of Structural Engineering, 119(12), 3590-3610.

Winistörfer, A.U., 1999, Development of Non-laminated Advanced Composite Straps for Civil Engineering Applications, PhD Thesis, Department of Engineering, University of Warwick.

Yapa, H.D., 2011, Optimum Shear Strengthening of Reinforced Concrete Beams, PhD Thesis, Department of Engineering, University of Cambridge.

Yapa, H.D. and Lees, J.M. 2011, Analysis of CFRP Strap-Strengthened Reinforced Concrete Beams Using the Modified Compression Field Theory (MCFT). In: FiberReinforced Polymer (FRP) Reinforcement for Concrete Structures. American Concrete Institute, SP 275, 1-20. 


\section{List of Tables and Figures}

Table 1. Design data and results for the experimental beams

Table 2. MCFT results for the experimental beams

Figure1. CFRP strap shear strengthening system

Figure 2. Concrete in tension: (a) stress-strain behavior; (b) slipping strain vs. crack angle

Figure 3. Concrete compression softening model for $f_{c}^{\prime}=-35 \mathrm{MPa}$ (a) 1986 model; (b) 1993 A model; (c) comparison of 1986 and 1993 A models for $\varepsilon_{1}=0.0027$ and 0.005

Figure 4. (a) Vertical stress approximation for nonuniform strap configurations; (b) confined area ratio

Figure 5. (a) Beam cross section; (b) internal and external reinforcement layouts and strain gauge locations (dimensions in millimeters)

Figure 6. Test rig

Figure 7. Load-displacement curves

Figure 8. Critical shear regions and photos taken at failure of the beams (dimensions in millimeters)

Figure 9. Comparison of strengthened beam experimental results with MCFT predictions: shear link stresses; CFRP strap force; and crack width for (a) B1; (b) B2; (c) B4; (d) B5; and (e) B6

Figure 10. Comparison of MCFT (a) shear stress; (b) compressive strength demand as a function of principal tensile strain 
Table 1. Design data and results for the experimental beams

\begin{tabular}{|c|c|c|c|c|c|c|c|c|}
\hline \multirow[b]{2}{*}{ Beam } & \multirow{2}{*}{$\begin{array}{c}-f_{c u} \\
(\mathrm{MPa})\end{array}$} & \multirow{2}{*}{ 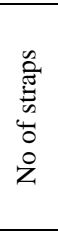 } & \multirow{2}{*}{ 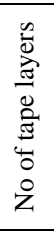 } & \multirow{2}{*}{ 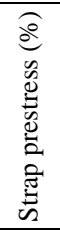 } & \multirow{2}{*}{ 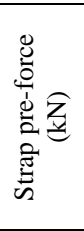 } & \multicolumn{2}{|c|}{ Ultimate load } & \multirow{2}{*}{$\frac{V_{M C F T}}{V_{E x p}}$} \\
\hline & & & & & & Exp & MCFT & \\
\hline B1 & 61.8 & 0 & - & - & - & 83.1 & 66.2 & 0.80 \\
\hline B2 & 42.8 & 2 & 10 & 25 & 15 & 104.7 & 105.2 & 1.00 \\
\hline B4 & 61.8 & 2 & 10 & 25 & 15 & 92.9 & 88.3 & 0.95 \\
\hline B5 & 47.8 & 3 & 5 & 25 & 7.5 & 114.8 & 111.0 & 0.97 \\
\hline B6 & 47.6 & 3 & 5 & 5 & 1.5 & 107.5 & 95.4 & 0.89 \\
\hline
\end{tabular}


Table 2. MCFT results for the experimental beams

\begin{tabular}{|c|c|c|c|c|c|c|c|c|c|c|c|c|c|}
\hline & $\begin{array}{c}\varepsilon_{1} \\
\times 10^{-3}\end{array}$ & $\begin{array}{c}\theta \\
\text { (deg) }\end{array}$ & $\begin{array}{c}f_{s z} \\
(\mathrm{MPa})\end{array}$ & $\frac{F_{F R P}}{F_{F R P_{-} U}}$ & $\begin{array}{c}w \\
(\mathrm{~mm})\end{array}$ & $\begin{array}{c}\varepsilon_{x} \\
\times 10^{-3}\end{array}$ & $\begin{array}{c}\varepsilon_{2} \\
\times 10^{-3}\end{array}$ & $\begin{array}{c}\gamma_{x z} \\
\times 10^{-3}\end{array}$ & $\begin{array}{c}f_{c 1} \\
(\mathrm{MPa})\end{array}$ & $\begin{array}{c}f_{c 2} \\
(\mathrm{MPa})\end{array}$ & $\stackrel{\varpi}{\omega}$ & $\frac{f_{c 2}}{f_{c 2 \max }}$ & $\begin{array}{c}V \\
(\mathrm{kN})\end{array}$ \\
\hline \multirow{7}{*}{$\bar{m}$} & 1.0 & 31.7 & 142 & - & 0.14 & 0.24 & -0.05 & 0.9 & 1.36 & -4.2 & - & 0.50 & 53.9 \\
\hline & 2.0 & 26.6 & 315 & - & 0.30 & 0.32 & -0.09 & 1.7 & 1.08 & -6.2 & $\mathrm{y}$ & 0.76 & 63.4 \\
\hline & 2.5 & 24.8 & 408 & - & 0.38 & 0.34 & -0.12 & 2.0 & 0.89 & -6.9 & $\mathrm{y}$ & 0.84 & 64.8 \\
\hline & 2.9 & 24.0 & 475 & - & 0.44 & 0.36 & -0.14 & 2.3 & 0.79 & -7.4 & $\mathrm{y}$ & 0.88 & 66.2 \\
\hline & 4.0 & 21.3 & 475 & - & 0.62 & 0.36 & -0.19 & 2.8 & 0.56 & -8.0 & $\mathrm{y}$ & 0.95 & 63.0 \\
\hline & 5.0 & 19.9 & 475 & - & 0.78 & 0.36 & -0.25 & 3.4 & 0.44 & -8.3 & $\mathrm{y}$ & 0.98 & 60.9 \\
\hline & 5.5 & 19.4 & 475 & - & 0.86 & 0.36 & -0.27 & 3.6 & 0.40 & -8.4 & $\mathrm{y}$ & 1.00 & 60.0 \\
\hline \multirow{6}{*}{ กี } & 1.0 & 34.8 & 130 & 0.29 & 0.14 & 0.25 & -0.11 & 1.0 & 1.13 & -5.2 & - & 0.48 & 64.7 \\
\hline & 2.0 & 30.1 & 290 & 0.34 & 0.29 & 0.35 & -0.20 & 1.9 & 0.97 & -7.9 & - & 0.75 & 83.4 \\
\hline & 2.7 & 29.1 & 370 & 0.36 & 0.37 & 0.39 & -0.26 & 2.3 & 0.90 & -8.9 & $\mathrm{y}$ & 0.84 & 90.7 \\
\hline & 3.2 & 28.0 & 475 & 0.39 & 0.47 & 0.43 & -0.35 & 2.9 & 0.75 & -10.1 & $\mathrm{y}$ & 0.92 & 97.5 \\
\hline & 4.0 & 27.0 & 475 & 0.44 & 0.59 & 0.46 & -0.46 & 3.6 & 0.62 & -10.9 & $\mathrm{y}$ & 0.97 & 101.2 \\
\hline & 5.0 & 26.3 & 475 & 0.48 & 0.75 & 0.48 & -0.61 & 4.5 & 0.52 & -11.7 & $\mathrm{y}$ & 1.00 & 105.2 \\
\hline \multirow{6}{*}{ 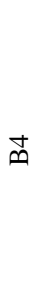 } & 1.0 & 35.1 & 130 & 0.29 & 0.14 & 0.29 & -0.06 & 1.0 & 1.36 & -4.6 & - & 0.48 & 60.0 \\
\hline & 2.0 & 29.7 & 296 & 0.34 & 0.29 & 0.40 & -0.12 & 1.8 & 1.16 & -7.2 & - & 0.75 & 78.0 \\
\hline & 2.4 & 28.5 & 364 & 0.36 & 0.35 & 0.43 & -0.15 & 2.1 & 1.08 & -8.1 & $\mathrm{y}$ & 0.82 & 83.4 \\
\hline & 3.1 & 26.9 & 475 & 0.39 & 0.46 & 0.47 & -0.20 & 2.7 & 0.87 & -9.1 & $\mathrm{y}$ & 0.90 & 87.7 \\
\hline & 4.0 & 24.9 & 475 & 0.44 & 0.60 & 0.48 & -0.27 & 3.3 & 0.68 & -9.9 & $\mathrm{y}$ & 0.96 & 87.8 \\
\hline & 5.0 & 23.5 & 475 & 0.50 & 0.76 & 0.49 & -0.35 & 3.9 & 0.54 & -10.6 & $\mathrm{y}$ & 1.00 & 88.3 \\
\hline \multirow{6}{*}{$\stackrel{\varphi}{\oplus}$} & 1.0 & 35.1 & 130 & 0.29 & 0.14 & 0.26 & -0.10 & 1.0 & 1.20 & -5.4 & - & 0.47 & 67.3 \\
\hline & 2.0 & 30.3 & 290 & 0.34 & 0.29 & 0.37 & -0.19 & 1.9 & 1.02 & -8.1 & - & 0.75 & 86.6 \\
\hline & 2.5 & 29.2 & 370 & 0.36 & 0.37 & 0.40 & -0.25 & 2.3 & 0.96 & -9.3 & $\mathrm{y}$ & 0.84 & 94.5 \\
\hline & 3.2 & 28.1 & 475 & 0.39 & 0.47 & 0.45 & -0.33 & 2.9 & 0.80 & -10.5 & $\mathrm{y}$ & 0.92 & 101.6 \\
\hline & 4.0 & 27.0 & 475 & 0.44 & 0.59 & 0.48 & -0.43 & 3.6 & 0.66 & -11.4 & $\mathrm{y}$ & 0.97 & 105.8 \\
\hline & 5.2 & 26.2 & 475 & 0.49 & 0.78 & 0.51 & -0.62 & 4.6 & 0.53 & -12.3 & $\mathrm{y}$ & 1.00 & 111.0 \\
\hline \multirow{6}{*}{$\mathscr{n}$} & 1.0 & 32.0 & 140 & 0.09 & 0.15 & 0.22 & -0.08 & 1.0 & 1.19 & -4.6 & - & 0.48 & 56.4 \\
\hline & 2.0 & 27.9 & 310 & 0.14 & 0.30 & 0.32 & -0.15 & 1.8 & 1.00 & -7.2 & $\mathrm{y}$ & 0.75 & 73.3 \\
\hline & 3.1 & 25.9 & 475 & 0.19 & 0.46 & 0.38 & -0.26 & 2.6 & 0.73 & -9 & $\mathrm{y}$ & 0.90 & 83.2 \\
\hline & 4.0 & 24.8 & 475 & 0.24 & 0.60 & 0.41 & -0.36 & 3.3 & 0.59 & -10 & $\mathrm{y}$ & 0.96 & 87.4 \\
\hline & 5.0 & 24.2 & 475 & 0.29 & 0.76 & 0.44 & -0.48 & 4.1 & 0.49 & -10.8 & $\mathrm{y}$ & 0.99 & 92.1 \\
\hline & 5.8 & 24.0 & 475 & 0.33 & 0.88 & 0.46 & -0.60 & 4.8 & 0.44 & -11.4 & $\mathrm{y}$ & 1.00 & 95.4 \\
\hline
\end{tabular}






Figure1. CFRP strap shear strengthening system

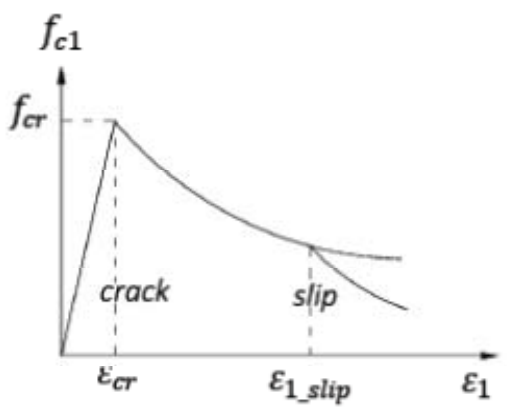

(a)

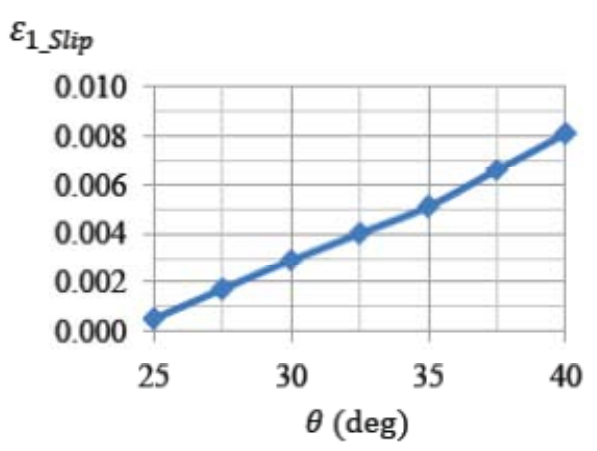

(b)

Figure 2. Concrete in tension: (a) stress-strain behavior; (b) slipping strain vs. crack angle

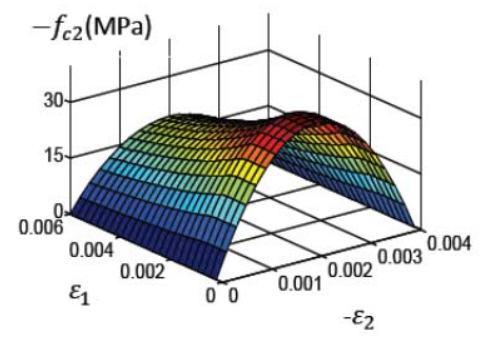

(a)

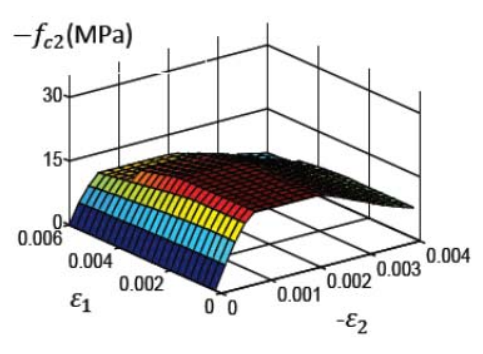

(b)

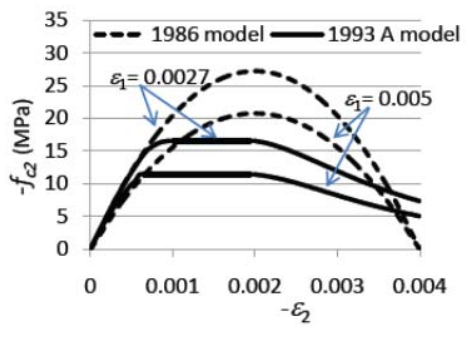

(c)

Figure 3. Concrete compression softening model for $f_{c}^{\prime}=-35 \mathrm{MPa}$ (a) 1986 model; (b) 1993 A model; (c) comparison of 1986 and 1993 A models for $\varepsilon_{1}=0.0027$ and 0.005 


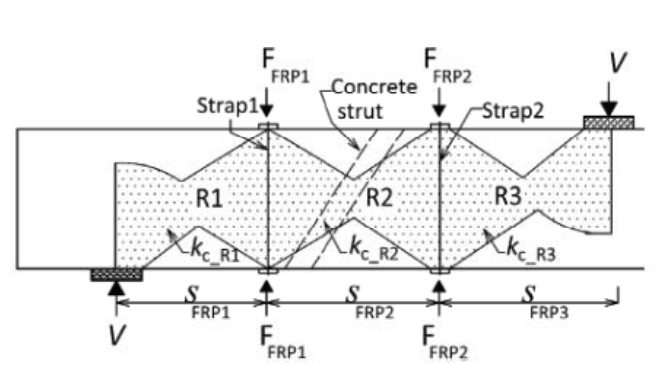

(a)

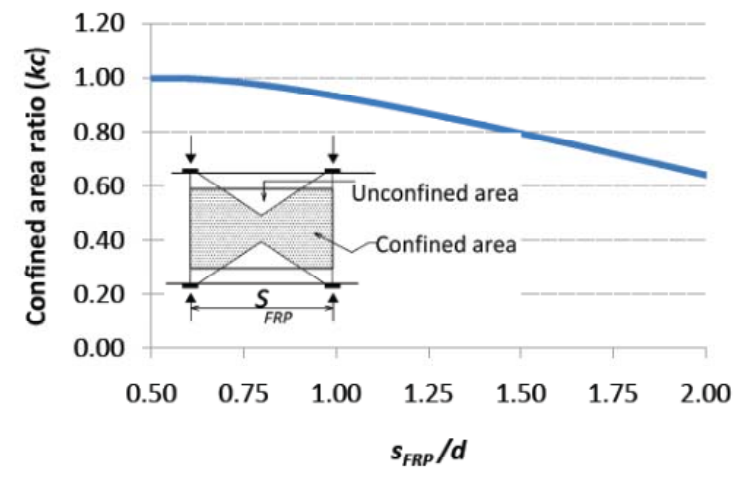

(b)

Figure 4. (a) Vertical stress approximation for nonuniform strap configurations; (b) confined area ratio

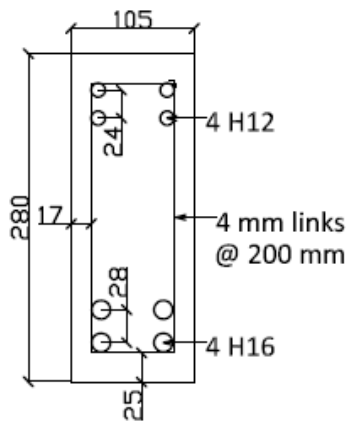

(a)
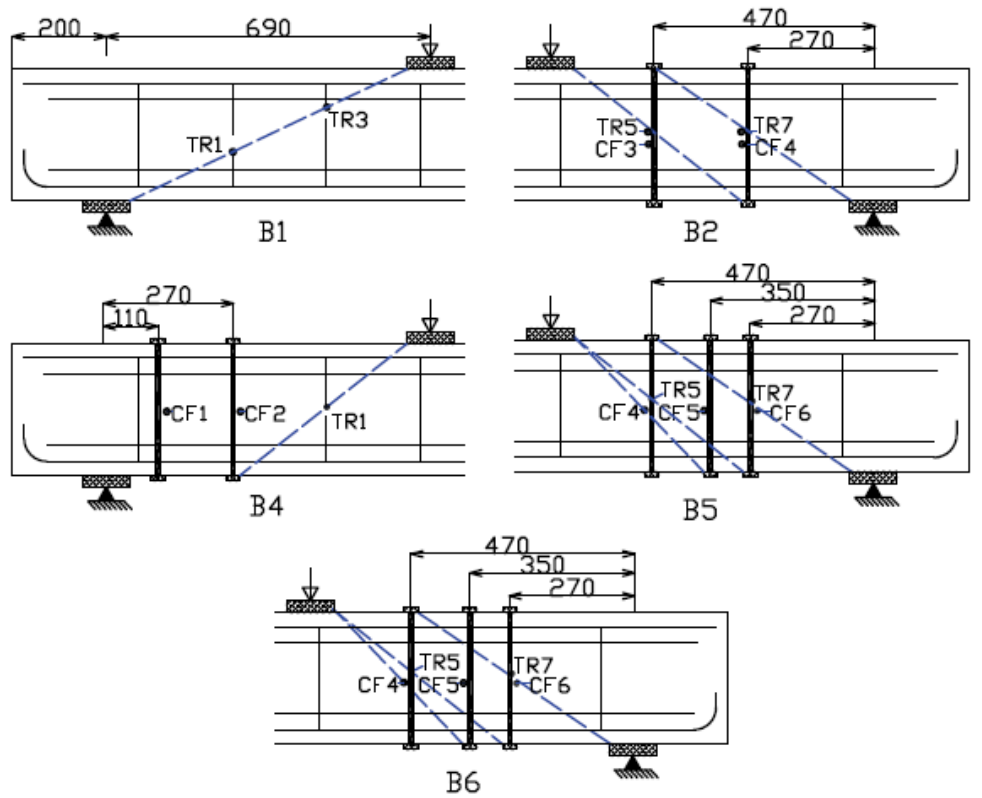

(b)

Figure 5. (a) Beam cross section; (b) internal and external reinforcement layouts and strain gauge locations (dimensions in millimeters) 


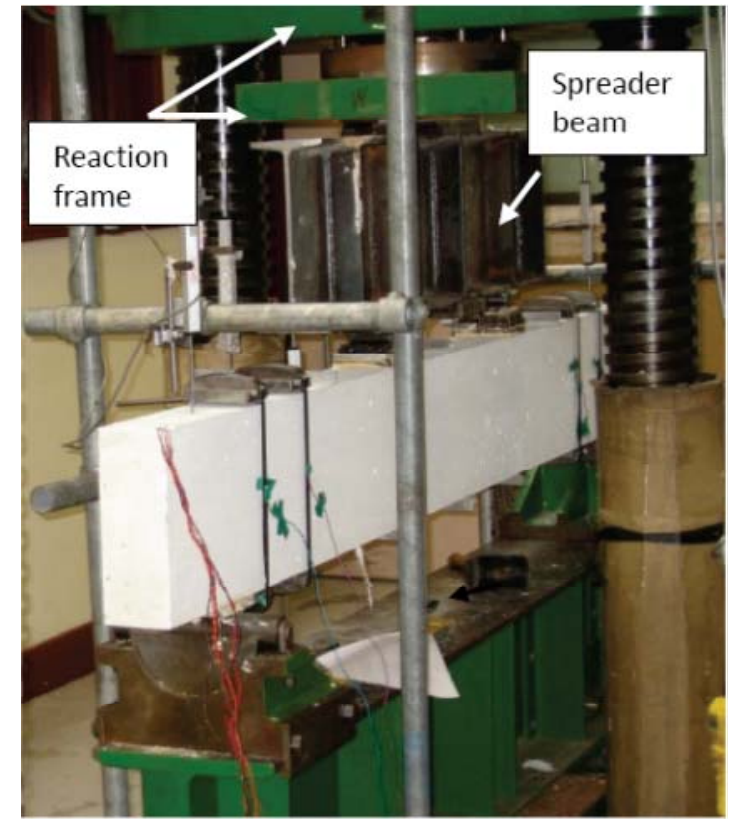

Figure 6. Test rig

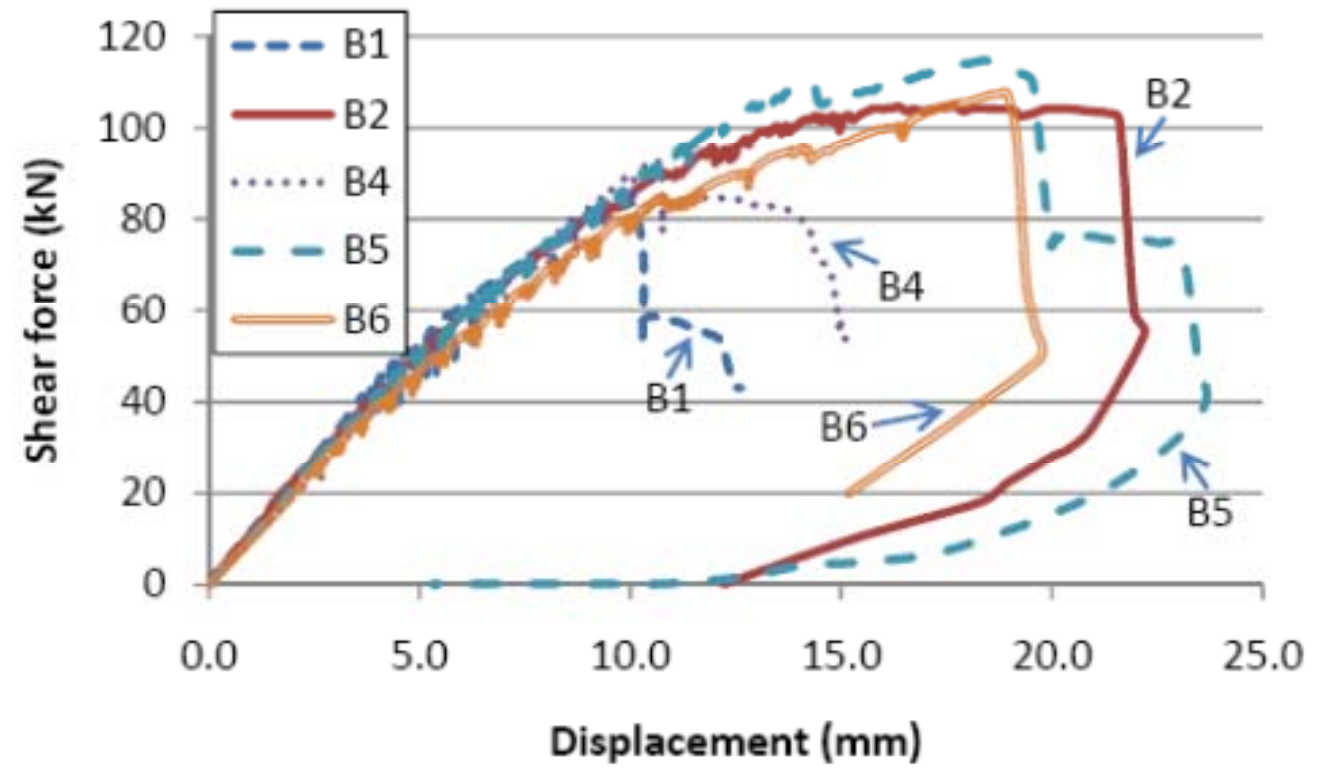

Figure 7. Load-displacement curves 


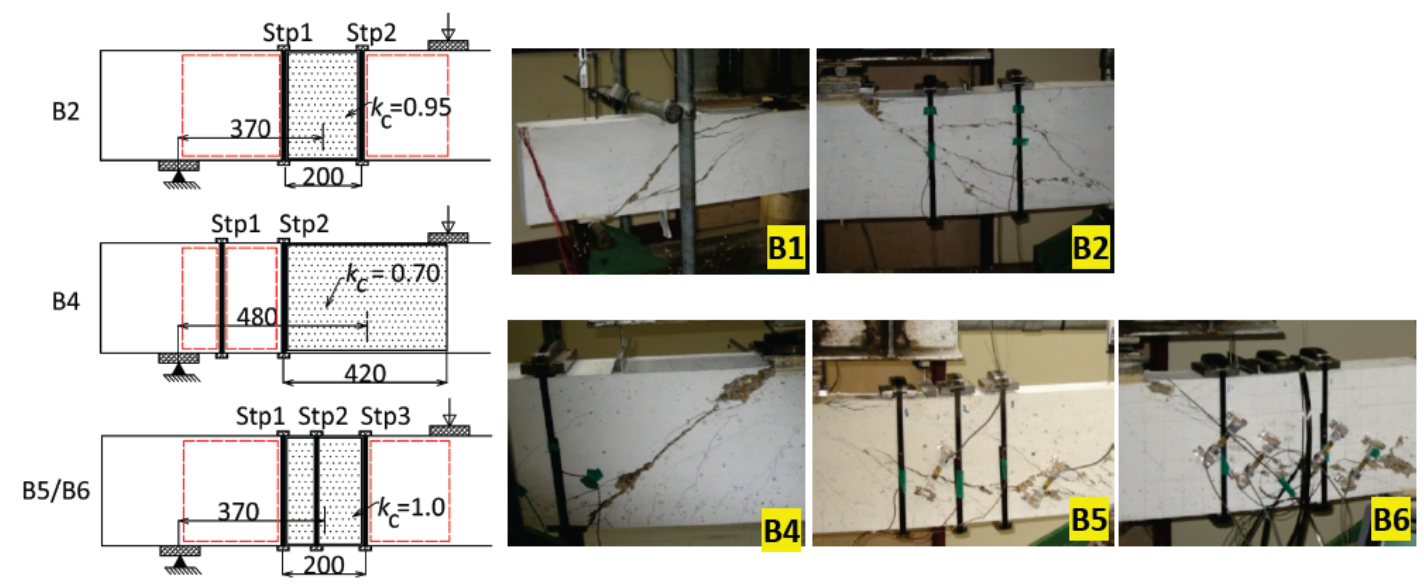

Figure 8. Critical shear regions and photos taken at failure of the beams (dimensions in millimeters) 


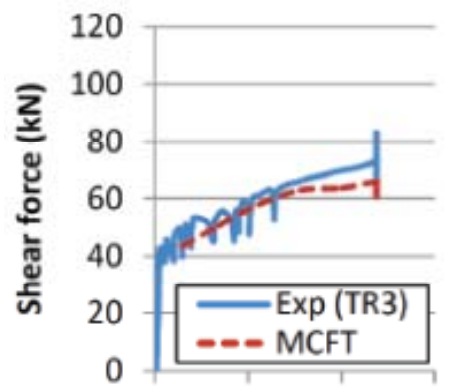

(a)
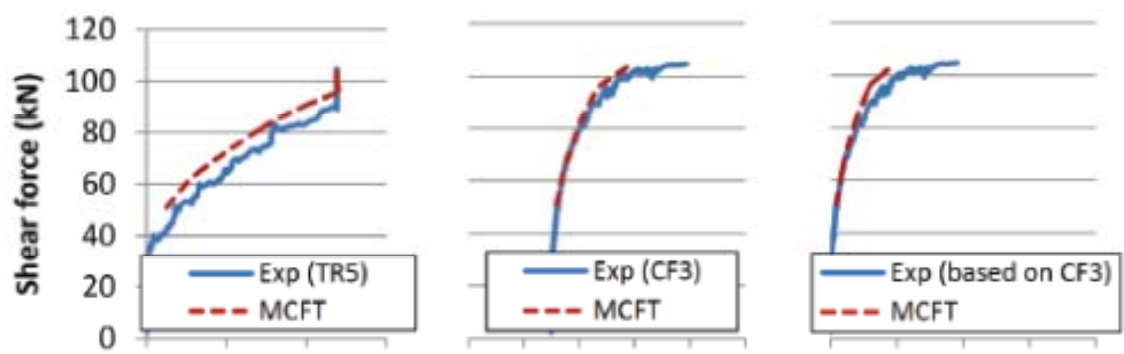

(b)
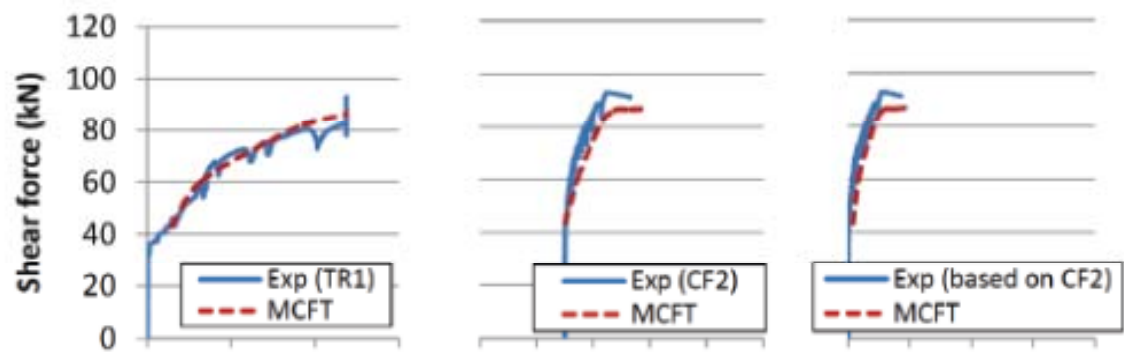

(c)
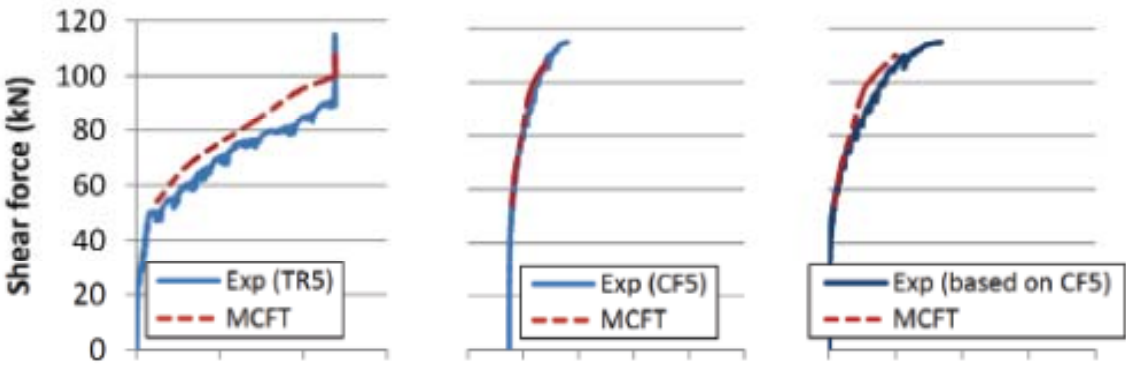

(d)

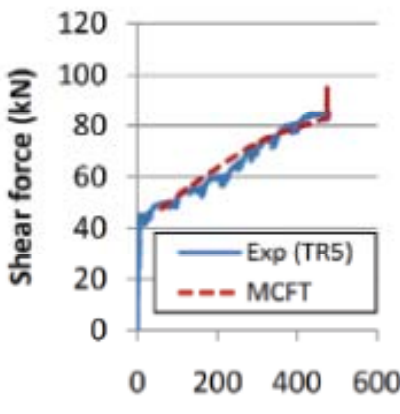

Shear link stress (MPa)
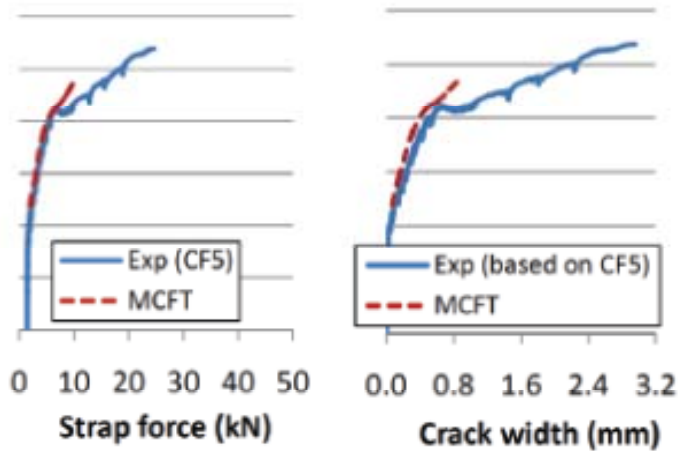

(e)

Figure 9. Comparison of strengthened beam experimental results with MCFT predictions: shear link stresses; CFRP strap force; and crack width for (a) B1; (b) B2; (c) B4; (d) B5; and (e) B6 


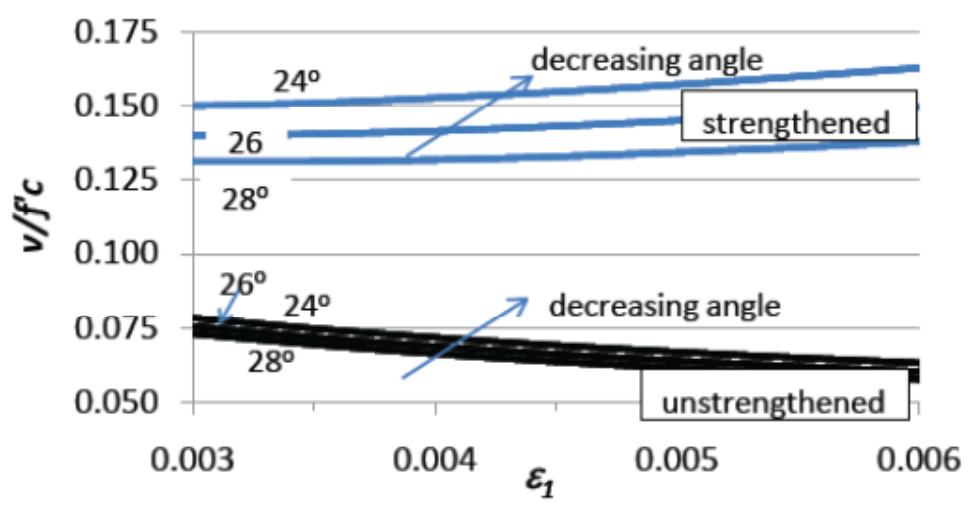

(a)

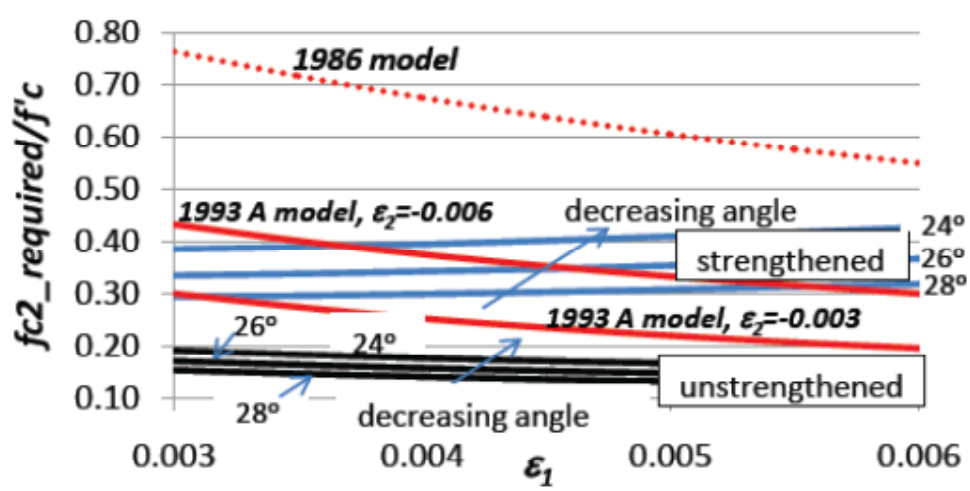

(b)

Figure 10. Comparison of MCFT (a) shear stress; (b) compressive strength demand as a function of principal tensile strain 